\title{
Prevalence, Etiology, and Risk Factors of Tinea Pedis and Tinea Unguium in Tunisia
}

\author{
Nourchène Toukabri, ${ }^{1}$ Cyrine Dhieb, ${ }^{1}$ Dalenda El Euch, ${ }^{2}$ Mustapha Rouissi, ${ }^{3}$ \\ Mourad Mokni, ${ }^{2}$ and Najla Sadfi-Zouaoui ${ }^{1}$ \\ ${ }^{1}$ Laboratoire de Mycologie, Pathologies et Biomarqueurs, Faculté des Sciences de Tunis, Université Tunis El Manar, 2092 Tunis, Tunisia \\ ${ }^{2}$ Service de Dermatologie et de Vénéréologie, Hôpital La Rabta, Tunis, Tunisia \\ ${ }^{3}$ Institut National de la Recherche Agronomique de Tunis, Tunis, Tunisia \\ Correspondence should be addressed to Najla Sadfi-Zouaoui; sadfi.najla@gmail.com
}

Received 15 March 2017; Revised 6 June 2017; Accepted 22 June 2017; Published 9 August 2017

Academic Editor: Maria L. Tornesello

Copyright (C) 2017 Nourchène Toukabri et al. This is an open access article distributed under the Creative Commons Attribution License, which permits unrestricted use, distribution, and reproduction in any medium, provided the original work is properly cited.

Background. Foot mycoses are a frequent disease that represents a public health problem worldwide. Objectives. This study aims to evaluate the epidemiology of foot mycoses among Tunisian patients, in order to determine the fungal etiological agents and to identify possible risk factors. Patients and Methods. A prospective study of three hundred and ninety-two patients was undertaken during one year (2013-2014). All subjects were asked to collect demographic data related to the risk factors of foot mycoses. A complete mycological diagnosis was carried out on all patients. Results. A total of 485 samples were collected; tinea pedis and tinea unguium were confirmed in $88.2 \%$ of cases. Dermatophytes were isolated in $70.5 \%$ and the most frequent pathogen was Trichophyton rubrum (98.1\%), followed by yeasts (17.7\%) commonly Candida parapsilosis. Non-dermatophyte molds (NDMs) were observed in $8.02 \%$ cases and Fusarium sp. was the frequent genus (29.1\%). The main predisposing factors of fungal foot infections were practicing ritual washing (56.6\%) and frequentation of communal showers (50.5\%). Conclusion. This is a recent survey of foot mycoses in Tunisia. Epidemiological studies can be useful to eradicate these infections and to provide further measures of hygiene and education.

\section{Introduction}

Fungal infections of the feet including tinea pedis and tinea unguium are very common in the general population [1]. Tinea pedis, generally known as athlete's foot, is divided into three clinical forms such as interdigital, plantar (moccasin foot), and vesiculobullous [2]. Interdigital is the most common clinical manifestation characterized by maceration and fissuring of the skin mainly in the space between the toes. Plantar athlete's foot presents with hyperkeratosic and squamous plaques which cover the soles, heels, and sides of the foot. In inflammatory condition vesicles, pustules and sometimes bullae are present on the sole of the foot [3]. Tinea unguium is classified into four clinical types depending on the mode of penetration of the fungus in the nail plate: distal lateral subungual onychomycosis (DLSO); proximal subungual onychomycosis (PSO); white superficial onychomycosis (WSO); and total dystrophic onychomycosis (TDO) [4].

Because of the prolonged period of treatment and the recurrence of infections, foot mycoses are still considered as a major public health problem affecting quality of life [5]. These fungal infections depends on many factors especially lifestyle and environmental and climatic conditions and can be influenced by individual factors such as age and host defenses [6]. Foot mycoses are mainly caused by dermatophytes, sometimes yeasts, and uncommonly by non-dermatophyte molds (NDMs).

Many epidemiological studies have investigated the variability of the frequency of tinea pedis and tinea unguium in different geographical regions [7-11]. In fact, the practice of epidemiological studies at regular intervals is necessary for 
TABLE 1: Distribution of foot mycosis according to sex.

\begin{tabular}{|c|c|c|c|c|c|}
\hline & \multicolumn{2}{|c|}{ Males } & \multicolumn{2}{|c|}{ Females } & \multirow{2}{*}{$p$ valu } \\
\hline & Number & $\%$ & Number & $\%$ & \\
\hline Positive & 114 & 91.20 & 232 & 86.89 & \\
\hline Negative & 11 & 8.80 & 35 & 13.10 & 0.217 \\
\hline Total & 125 & 31.88 & 267 & 68.11 & \\
\hline
\end{tabular}

monitoring the evolution of foot mycoses over time. To our knowledge, there are few recent studies regarding clinical and mycological features of foot mycoses in Tunisia. The aim of our study was to determine the frequency of foot mycoses, their clinical patterns, predisposing factors, and etiological agents in Tunisian patients.

\section{Patients and Methods}

It was a prospective study that was carried during one year from March 2013 and included all patients referred to the Mycology Unit in the Department of Dermatology and Venereology of La Rabta Universal Hospital in Tunis (Tunisia). Three hundred ninety-two patients were examined to establish the presence of clinical signs of tinea unguium and/or tinea pedis. The questionnaire allowed documentation of potential predisposing factors for foot mycoses, age, sex, diabetes, vascular disease, immunosuppressive drug treatment, psoriasis, fungal infection of the skin, dermatological pathology, associated fingernails onychomycosis, family history of foot mycoses, ritual religious washing, physical activities, used shoes, occlusive shoes, using of publics showers, swimming pools, smoking, walking barefoot, thermal station, pedicure, and the application of henna. Also, the type of tinea pedis (interdigital, hyperkeratosis, and dyshidrosis) and the type of tinea unguium (DLSO, PSO, WSO, or TDO) were documented.

Clinical specimens of skin scrapings and nail clippings were collected in sterile Petri dishes for direct examination and culture. All specimens were submitted to a microscopic examination in Chlorazol noir (Sigma-Aldrich, Germany) solution and inoculated into Sabouraud chloramphenicol dextrose agar with and without cycloheximide (Biorad, France) all in duplicate. The culture was incubated at $27^{\circ} \mathrm{C}$ and examined after $48-72 \mathrm{~h}$ for yeast detection and every four days for at least four weeks for fungal detection.

The identification of filamentous fungi was based on macroscopic and microscopic examination in the Lactophenol Cotton Blue (Sigma-Aldrich, Germany). The identification of yeast was carried out using the API ID 32C system (Biomerieux, France). The mycological examination was considered to be positive if direct microscopic examination and/or culture were positive. In the absence of any dermatophyte or yeast growth, a mold was only considered to be the causal agent of onychomycosis when the culture was repeated on two separate occasions.

Statistical analysis was performed with SPSS software (Statistical Package for Social Scientists version 20.0, SPSS, Inc., Armonk, NY). The Chi-square $\left(\chi^{2}\right)$ was used to calculate significant differences in characteristics between patients. Differences with $p<0.05$ were considered statistically significant.

\section{Results}

A total of 392 patients from various regions in Tunisia were included in this study, 125 males $(31.88 \%)$ and 267 females $(68.11 \%)$, with an age range between 3 and 85 years and an average age of 44.7 years. The diagnosis of foot mycosis was confirmed through a mycological diagnosis in $346(88.26 \%)$ cases; the frequency was higher in females (67.05\%) compared with males (32.94\%) but this prevalence according to the sex was not statistically significant $(p=0.217)$ (Table 1$)$.

As shown in Figure 1, the frequency of foot mycoses according to the age groups revealed that the patients most commonly infected were between 41 and 50 years $(23.1 \%)$ followed by those between 51 and 60 years (21.9\%) but the differences were not statistically significant $(p=0.0658$; $p=0.71$, resp.). However, the prevalence was less frequent in children less than 10 years old $(0.8 \%)$ and this prevalence was significant $(p=0.0126)$.

Related to the site of infection, we noted that tinea unguium was confirmed in 268 subjects $(77.4 \%)$ and tinea pedis was confirmed in 78 cases $(22.5 \%)$. The subtype most frequently observed in tinea pedis was plantar keratoderma in 70 cases $(89.7 \%)$, followed by interdigital 23 cases $(29.4 \%)$. 57 cases $(73.07 \%)$ of the subjects whom presented with tinea pedis have toenail onychomycosis (Table 2 ).

Clinical patterns of foot mycoses are cited in Table 3; DLSO represent the most common clinical form of tinea unguium (64.3\%) followed by TDO (15.6\%) and SWO (12.9\%). The big toenail was the most infected in 114 cases (35.07\%), bilateral nail infection was observed in 55 cases (16.9\%), and multiple toes were affected in 103 cases (31.6\%). For tinea pedis plantar hyperkeratosis form was observed in 44 cases $(62.8 \%)$ and plantar dyshidrosis in 26 cases (37.1\%). A total of 485 samples were collected from all patients; the direct microscopic examination was positive in 385 specimens (79.3\%) showing filaments in 371 cases (96.3\%), yeast and pseudomycelium in two cases $(0.5 \%)$, and both filaments with spores in 12 cases $(3.1 \%)$.

We have obtained 299 positive cultures (61.6\%), including dermatophytes in 211 cases (70.5\%), yeasts in $53(17.7 \%)$, NDMs in 24 cases $(8.02 \%)$, and mixed culture (dermatophytes + yeast) in 11 cases (3.6\%). The most frequently isolated dermatophyte was Trichophyton rubrum (98.1\%), followed by T. violaceum, T. tonsurans, T. verrucosum, and T. interdigitale with $0.47 \%$ for each species. While Candida parapsilosis 
TABLE 2: Distribution of foot mycoses according to anatomic sites.

\begin{tabular}{|c|c|c|c|c|c|c|}
\hline \multirow{2}{*}{ Nature of lesion } & \multirow{2}{*}{ Site of infection } & \multirow{2}{*}{ Number of patients } & \multicolumn{2}{|c|}{ Direct examination } & \multicolumn{2}{|c|}{ Culture } \\
\hline & & & $(+)$ & $(-)$ & $(+)$ & $(-)$ \\
\hline Tinea unguium & Nails & 268 & 253 & 15 & 201 & 67 \\
\hline \multirow[t]{6}{*}{ Tinea pedis } & Interdigital & 3 & 2 & 1 & 3 & 0 \\
\hline & Plantar & 14 & 13 & 1 & 6 & 8 \\
\hline & Interdigital and plantar & 4 & 4 & 0 & 3 & 1 \\
\hline & Interdigital and nails & 5 & 5 & 0 & 5 & 0 \\
\hline & Plantar and nails & 41 & 41 & 0 & 33 & 8 \\
\hline & Interdigital, plantar, and nails & 11 & 10 & 1 & 7 & 4 \\
\hline Total & & 346 & 328 & 18 & 258 & 88 \\
\hline
\end{tabular}

(+): positive; (-): negative.

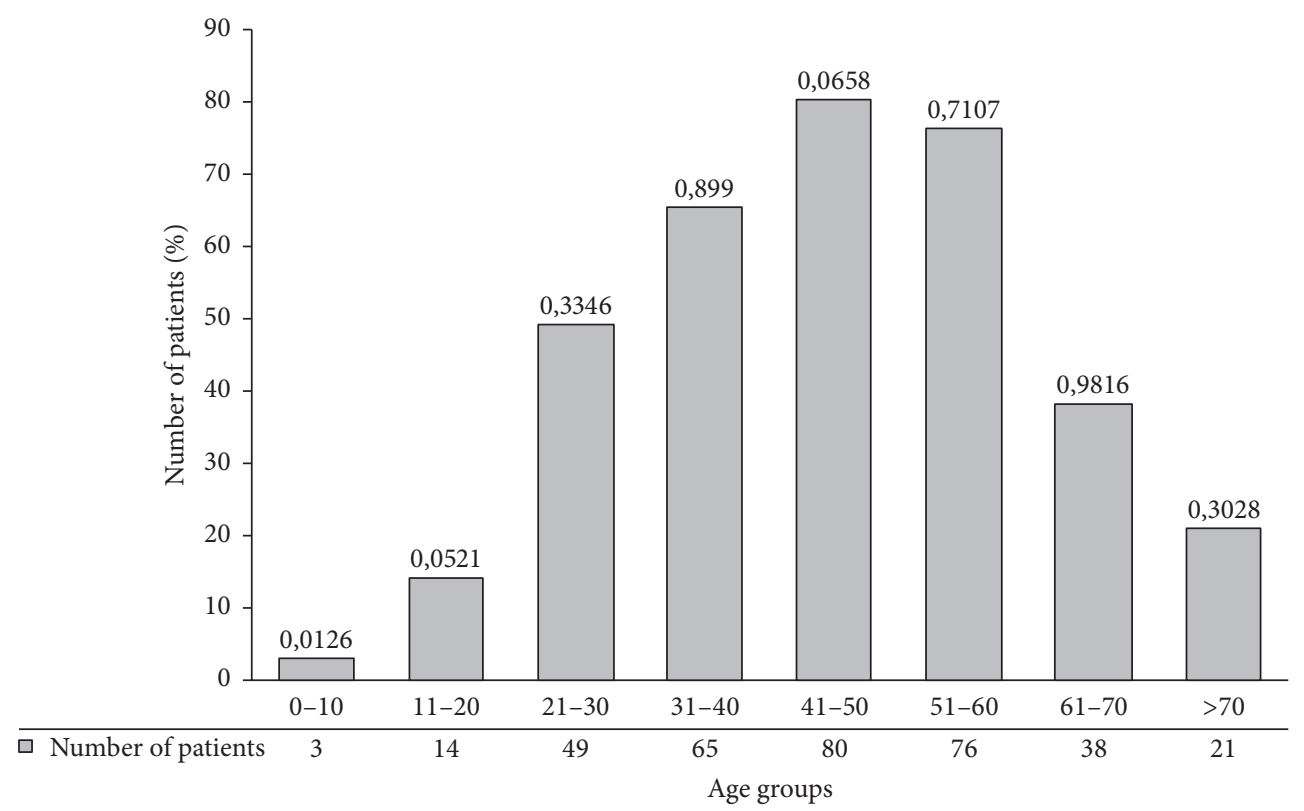

Figure 1: Frequency of foot mycoses according to age groups. Percentage of patients with foot mycoses according to different age groups. $p$ value is mentioned under each histogram.

TABLE 3: Clinical patterns of foot mycoses.

\begin{tabular}{lc}
\hline Clinical patterns & Number of cases (\%) \\
\hline Tinea unguium & $325(100)$ \\
DLSO & $209(64.3)$ \\
PSO & $23(7.07)$ \\
SWO & $42(12.9)$ \\
TDO & $51(15.6)$ \\
Tinea pedis & $78(100)$ \\
Plantar hyperkeratosis & $44(62.8)$ \\
Plantar dyshidrosis & $26(37.1)$ \\
Interdigital & $23(29.4)$ \\
\hline
\end{tabular}

DLSO, distal lateral subungual onychomycosis; PSO, proximal subungual onychomycosis; SWO, superficial white onychomycosis; TDO, total dystrophic onychomycosis.

was the most isolated yeast (60.3\%), also Trichosporon spp. were isolated $(3.7 \%)$. The remaining were due to NDMs like Fusarium (29.1\%), Penicillium (25\%), Aspergillus (20.8\%), Scopulariopsis (16.6\%), and Scytalidium (8.3\%). In mixed culture, C. parapsilosis was most frequently detected with $T$. rubrum $(72.7 \%)$ (Table 4$)$.

Since our survey was conducted during one year, we have seen a lower frequency of patients in the winter (16.5\%) and most cases were observed in spring (33.4\%) and the summer (21.1\%) (Figure 2).

Considering the possible risk factors, we noted that the high prevalence was observed in patients who practice ritual ablutions (56.6\%) followed by communal shower $(50.5 \%)$ and family history of foot mycoses $(28.6 \%)$ but there was no statistically significant association between these factors and foot infection ( $p=0.41,0.631$, and 0.246 , resp.). However, we noted a significant association between foot mycoses and nail trauma $(26.5 \% ; p=0.019)$, wearing used shoes $(26.3 \% ; p=0.001)$, antifungal drugs $(25.7 \% ; p=$ $0.013)$, physical activities $(14.7 \% ; p=0.049)$, occlusive shoes (13.2\%; $p=0.008)$, swimming pools (8.09\%; $p=0.045)$, 
TABLE 4: Etiological agents responsible for foot mycoses.

\begin{tabular}{|c|c|c|c|}
\hline Causative agents & Tinea unguium & Tinea pedis & Total (\%) \\
\hline Dermatophytes & 165 & 46 & $211(70.5)$ \\
\hline T. rubrum & 163 & 44 & $207(98.1)$ \\
\hline T. violaceum & - & 1 & $1(0.47)$ \\
\hline T. tonsurans & 1 & - & $1(0.47)$ \\
\hline T. verrucosum & - & 1 & $1(0.47)$ \\
\hline T. interdigitale & 1 & - & $1(0.47)$ \\
\hline Yeasts & 53 & - & $53(17.7)$ \\
\hline C. parapsilosis & 32 & - & $32(60.3)$ \\
\hline C. tropicalis & 1 & - & $1(1.8)$ \\
\hline C. metapsilosis & 2 & - & $2(3.7)$ \\
\hline C. famata & 2 & - & $2(3.7)$ \\
\hline C. lusitaniae & 1 & - & $1(1.8)$ \\
\hline C. pelliculosa & 1 & - & $1(1.8)$ \\
\hline C. sake & 2 & - & $2(3.7)$ \\
\hline C. guilliermondii & 5 & - & $5(9.4)$ \\
\hline Trichosporon asahii & 1 & - & $1(1.8)$ \\
\hline Trichosporon mucoides & 1 & - & $1(1.8)$ \\
\hline Rhodotorula & 1 & - & $1(1.8)$ \\
\hline Other Candida sp. & 4 & - & $4(7.5)$ \\
\hline NDMs & 24 & - & $24(8.02)$ \\
\hline Aspergillus sp. & 5 & - & $5(20.8)$ \\
\hline Fusarium sp. & 7 & - & $7(29.1)$ \\
\hline Scopulariopsis brevicaulis & 4 & - & $4(16.6)$ \\
\hline Penicillium sp. & 6 & - & $6(25)$ \\
\hline Scytalidium & 2 & - & $2(8.3)$ \\
\hline Mixed culture & 10 & 1 & $11(3.6)$ \\
\hline T. rubrum + C. parapsilosis & 7 & 1 & $8(72.7)$ \\
\hline T. rubrum + C. metapsilosis & 1 & - & $1(9.09)$ \\
\hline T. rubrum + Trichosporon sp. & 1 & - & $1(9.09)$ \\
\hline T. rubrum + Rhodotorula & 1 & - & $1(9.09)$ \\
\hline
\end{tabular}

C., Candida; T., Trichophyton; NDMs, non-dermatophyte molds.

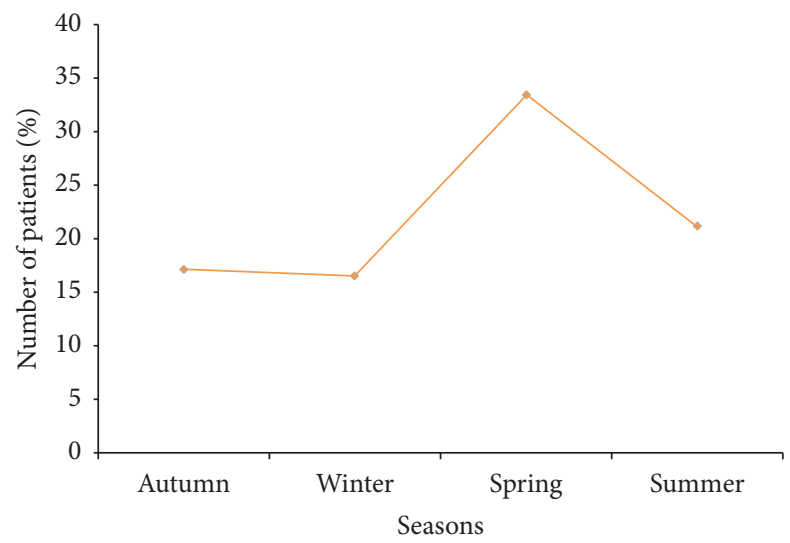

FIgURE 2: Seasonal evolution of fungal infections of the feet. Percentage of patients consulted during the four seasons.

attending thermal station $(8.3 \% ; p=0.021)$, pedicure $(14.1 \%$; $p=0.006)$, associated fingernails onychomycosis $(7.5 \% ; p=$
0.010), and those taking immunosuppressive drugs (5.4\%; $p=0.018$ ).

In our study, we did not find a significant association between foot mycoses and diabetes, vascular disease, psoriasis, fungal infection of the skin, dermatological pathology, smoking, obesity, walking barefoot, and the application of henna $(p>0.05)$ (Table 5).

\section{Discussion}

Foot mycosis is the most common superficial infection and represents a major public health problem over the world. Many epidemiological studies have reported the high frequency of this fungal infection, but the prevalence varies with many factors like geographic and demographic parameters and the number of selected population. To our knowledge, the latest epidemiological studies about foot mycoses in Tunisia were established by El Fekih et al. [12] in Tunisia between January and April 2009 and by Dhib et al. [13] during 22 years from 1986 to 2007 in the center of Tunisia (Sousse). 
TABLE 5: Possible risk factors associated with foot mycosis based on the questionnaire.

\begin{tabular}{|c|c|c|c|}
\hline \multirow{2}{*}{ Risk factors } & \multicolumn{2}{|c|}{ Patients with foot mycosis } & \multirow{2}{*}{$p$ value } \\
\hline & Number & $\%$ & \\
\hline \multicolumn{4}{|c|}{ Chronic diseases } \\
\hline \multicolumn{4}{|c|}{ Diabetes history } \\
\hline Present & 41 & 11.8 & \multirow{2}{*}{0.815} \\
\hline Absent & 305 & 88.1 & \\
\hline \multicolumn{4}{|c|}{ Peripheral vascular disease } \\
\hline Present & 76 & 21.9 & \multirow{2}{*}{0.293} \\
\hline Absent & 270 & 78.03 & \\
\hline \multicolumn{4}{|c|}{ Immunosuppressive drugs } \\
\hline Present & 19 & 5.4 & \multirow{2}{*}{0.018} \\
\hline Absent & 327 & 94.5 & \\
\hline \multicolumn{4}{|l|}{ Skin disorders } \\
\hline \multicolumn{4}{|l|}{ Psoriasis } \\
\hline Present & 6 & 1.7 & \multirow{2}{*}{0,368} \\
\hline Absent & 340 & 98.2 & \\
\hline \multicolumn{4}{|c|}{ Fungal infection of the skin } \\
\hline Present & 7 & 2.02 & \multirow{2}{*}{0,330} \\
\hline Absent & 339 & 97.9 & \\
\hline \multicolumn{4}{|c|}{ Dermatological pathology } \\
\hline Present & 11 & 3.1 & \multirow{2}{*}{0.220} \\
\hline Absent & 335 & 96.8 & \\
\hline \multicolumn{4}{|c|}{ Associated fingernails onychomycosis } \\
\hline Present & 26 & 7.5 & \multirow{2}{*}{0.010} \\
\hline Absent & 320 & 92.4 & \\
\hline \multicolumn{4}{|l|}{ Life style } \\
\hline \multicolumn{4}{|c|}{ Family history of foot mycosis } \\
\hline Present & 99 & 28.6 & \multirow{2}{*}{0.244} \\
\hline Absent & 247 & 71.3 & \\
\hline Ritual wash & & & \\
\hline Present & 196 & 56.6 & 0.410 \\
\hline Absent & 150 & 43.3 & 0.410 \\
\hline Physical act & & & \\
\hline Present & 51 & 14.7 & 0.049 \\
\hline Absent & 295 & 85.2 & 0.049 \\
\hline Wearing use & & & \\
\hline Present & 91 & 26.3 & 0.001 \\
\hline Absent & 255 & 73.6 & \\
\hline Occlusive sh & & & \\
\hline Present & 46 & 13.2 & \\
\hline Absent & 300 & 86.8 & 0,008 \\
\hline Nail traumo & & & \\
\hline Present & 92 & 26.5 & 0.019 \\
\hline Absent & 254 & 73.4 & 0.013 \\
\hline Swimming & & & \\
\hline Present & 28 & 8.09 & 0,045 \\
\hline Absent & 318 & 91.9 & $0,04 J$ \\
\hline Communal & & & \\
\hline Present & 175 & 50.5 & 0.631 \\
\hline Absent & 171 & 49.4 & 0.031 \\
\hline
\end{tabular}


TABLE 5: Continued.

\begin{tabular}{|c|c|c|c|}
\hline \multirow{2}{*}{ Risk factors } & \multicolumn{2}{|c|}{ Patients with foot mycosis } & \multirow{2}{*}{$p$ value } \\
\hline & Number & $\%$ & \\
\hline \multicolumn{4}{|l|}{ Smoking } \\
\hline Present & 13 & 3.7 & \multirow{2}{*}{0,181} \\
\hline Absent & 333 & 96.2 & \\
\hline \multicolumn{4}{|l|}{ Obesity } \\
\hline Present & 8 & 2.3 & \multirow{2}{*}{0.297} \\
\hline Absent & 338 & 97.6 & \\
\hline \multicolumn{4}{|c|}{ Walking barefoot } \\
\hline Present & 34 & 9.82 & \multirow{2}{*}{0,524} \\
\hline Absent & 312 & 90.1 & \\
\hline \multicolumn{4}{|c|}{ Thermal station } \\
\hline Present & 29 & 8.3 & \multirow{2}{*}{0.021} \\
\hline Absent & 317 & 91.6 & \\
\hline \multicolumn{4}{|l|}{ Pedicure } \\
\hline Present & 49 & 14.1 & \multirow{2}{*}{0,006} \\
\hline Absent & 297 & 85.9 & \\
\hline \multicolumn{4}{|c|}{ Application of henna } \\
\hline Present & 6 & 1.73 & \multirow{2}{*}{0.832} \\
\hline Absent & 340 & 98.2 & \\
\hline \multicolumn{4}{|c|}{ Antifungal therapy } \\
\hline Present & 89 & 25.7 & \multirow{2}{*}{0.013} \\
\hline Absent & 257 & 74.2 & \\
\hline
\end{tabular}

In the present study, the prevalence of tinea unguium and tinea pedis in the population studied were $77.4 \%$ and $22.5 \%$, respectively; females were more commonly affected than males which agree with some reports [14-16]. But there was no significant relationship in the occurrence of foot mycoses with respect to the sex and these results are in accordance with Dhib et al. [13]. This may be caused by aesthetics reasons such as repeated aggressive pedicure and manicure, frequent housework, and using detergents that cause nail trauma and generally females consulted more frequently for onychomycosis. However, several studies concluded that males are more infected than females due to the fact that males are more exposed to nail trauma and using occlusive footwear $[1,17]$.

The frequency of tinea pedis and tinea unguium increased gradually with age; a maximum prevalence was seen in adults aged between 31 and 60 years. These results were confirmed by many studies [10,12, 18], and this increase may be explained by many conditions such as full-time work activities, frequent nail trauma, reduced nail growth, and inadequate foot care [19]. However, the frequency is less prevalent in the elderly aged between 71 and 80 years and $>80$ years; this is in agreement with a study reported in Rio Grande do Sul, Brazil [20]. This decreasing frequency can be due to the negligence of old people who do not give importance to nail infections.

Our results also showed that children are rarely infected with foot mycoses; this frequency is in accordance with results observed in school children in Spain [21] and in Turkey [22]. Mycoses infections in children can be due to several factors including the difference in the nail plate, the rapid nail growth, and less exposure to fungal infection than adults.

Tinea pedis is known as the significant reservoir of other dermatophytes in the body and can be a cause of tinea unguium [23]. In the current study, tinea pedis was associated with tinea unguium in more than half of cases (73.07\%); this rate was higher than reported in USA [24], in Tokyo [17], and even in another study in Tunisia [12]. This association confirmed the hypothesis that the toenails were infected by toe-webs.

Various clinical patterns of onychomycosis have been reported in the literature. In this work, DLSO was the most frequent clinical form as well as in other studies carried out in Turkey and in Tunisia [25-27]. The most affected toes were the big ones; this observation was expected because of the slow growth of the nail which facilitates the invasion of the pathogenic fungal.

In investigating the causative agents of tinea pedis and tinea unguium, we found that the most common isolated pathogens were dermatophytes $[28,29]$; among them, $T$. rubrum was the most common causative agent. These results are similar with other studies $[13,30-32]$ and are interpreted that $T$. rubrum is a virulent anthropophilic dermatophyte producing arthrospores which have the capacity to persist on the floor surface and on shoes. The second agent responsible for foot mycoses is yeasts, with a high frequency of $C$. parapsilosis. This agrees with the study of El Fekih et al. [12] and can be explained by the fact that C. parapsilosis represents a saprophyte yeast of the human skin. 
In our results, the anthropophilic $T$. violaceum was isolated from one patient with tinea pedis who had no history of tinea capitis, whereas this species has been classified as the second and the third etiological agent of onychomycosis in few cases as related agent to tinea capitis [26, 33].

Molds are cosmopolitan filamentous fungi; most of them are saprophyte and can be contaminants; however they become opportunistic under unfavorable conditions. In addition to the causative dermatophytes and yeasts, NDMs have been described as etiological agents of foot mycoses. Traditionally, these molds have been considered as secondary pathogens of nails which affect a keratin already degraded and their frequency rates between 1.45 and $17.6 \%$ [34]. The primary molds that cause onychomycosis are species belonging to the genus Scopulariopsis, Aspergillus, and Fusarium [35]. In our survey, we found a low incidence of NDMs and the most prevalent species were Fusarium sp. (29.1\%). This result agreed with the study reported in America showing that Fusarium spp. seem to be the most frequent agents [36].

In contrast, a study reported in Italy showed that Scopulariopsis brevicaulis was the dominant causative mold [37], although a recent paper from Morocco reports the increasing frequency of Aspergillus onychomycosis [38]. In the present work, two cases of onychomycosis were due to Scytalidium species. These molds caused lesions similar to those engendered by dermatophytes, called pseudodermatophytes, and widespread in the environment especially in tropical areas [39]. Walking barefoot represents the main risk factor of infections caused by these species because of their telluric reservoir. The presence of NDMs in foot mycoses may be related to many factors that predispose the development of nail infections, such as direct contact with the soil by walking barefoot, wearing open shoes sandals, practicing sports, and trauma of the nail.

Actually onychomycosis caused by NDMs is more prevalent in tropical and subtropical regions with a hot and humid climate making them endemic areas $[34,37]$.

The contaminated culture can be detected. This may be related to the nonpathogenic nature of the fungi that infects the nail or the presence of a saprophyte mold that inhibits the growth of the pathogenic fungi [11].

In the current study, we note that more cases of fungal infections of the foot were observed in the spring and the summer. The higher frequency during certain seasons can be related to the wearing of occlusive shoes in warm climates, causing heat of the feet which causes maceration and hyperhidrosis, considered as a risk factor of developing foot mycoses. In another way, patients become more aware that the duration of antifungal therapy requires a long period of time and prepare to wear summer shoes because they are more interested in beautiful feet.

Considering the risk factors of foot mycoses, we found a significant association with patients who practice physical activities [32], wear used shoes, or have frequent nail trauma [19] and with patients who receive immunosuppressive therapy [40].

Many other possible risk factors can be related to fungal infections of the foot but our study did not show a significant association; it was found to be most common in persons with family history of fungal infection of the foot [12], having peripheral vascular diseases [41]. Although foot mycoses can be linked to many chronic diseases like diabetes [42], HIV infection [43], and psoriasis [44], this can be explained that people with chronic infections are now more attentive to their health due to awareness raising sessions.

Interestingly, we found a high prevalence of subjects who practice ritual washing. Firstly, this can be explained by the religious custom of ablutions five times every day which can cause maceration of the feet which represents a risk factor of fungal penetration through the stratum corneum of the skin. It also can be related to the spread of fungal species in areas used for washing and in prayer carpets of the mosques; this has been confirmed in other studies [12, 45-47]. Moreover, in the current study, $50.5 \%$ of patients with foot mycoses attend communal showers and bathing. This high frequency may be the consequence of the culture and the tradition of Tunisian population to frequent hammams, which are humid and warm locations that are a source of fungal contagion; this also has been found in Algerian population [10, 48]

We observed that some patients have onyxis of both fingers and toes. The association of fingernails onychomycosis can be a risk factor for developing a foot infection that is reported in previous surveys $[13,19]$. This association can be related to autoinfection that represents an important source of transmission to another location of the same body [49].

In the present work, $25.7 \%$ subjects with foot mycosis have taken antifungal therapy. This finding may be related to the recurrent infection [50] that can be due to various causes which include lack of diagnosis, misidentification of the causative pathogen, and inappropriate choice of antifungal treatment. On the other hand, it can be related to resistant fungal species or the presence of dormant arthroconidia in the nail bed as a reservoir for recurrent infection [51].

\section{Conclusion}

The epidemiological profile of fungal foot infections seems to be related to age, life style, and the presence of comorbidities. Our study shows that the prevalence of these infections is common in the general population of Tunisia, and the frequency is higher than reported in Maghreb, African, and European countries. Our data can be useful to eradicate these infections and provide further measures regarding the personal hygiene and education about prophylaxis in order to reduce the risk factors of tinea pedis and tinea unguium.

\section{Disclosure}

The authors alone are responsible for the content and the writing of the paper.

\section{Conflicts of Interest}

The authors report no conflicts of interest. 


\section{Acknowledgments}

This work was supported by funds from the Ministry of Higher Education and Scientific Research of Tunisia (LR16ES05). The authors gratefully acknowledge the laboratory staff at La Rabta Hospital for the skilled technical assistance.

\section{References}

[1] S. Perea, M. J. Ramos, M. Garau, A. Gonzalez, A. R. Noriega, and A. Del Palacio, "Prevalence and risk factors of Tinea unguium and Tinea pedis in the general population in Spain," Journal of Clinical Microbiology, vol. 38, no. 9, pp. 3226-3230, 2000.

[2] T. J. Zuber and K. Baddam, "Superficial fungal infection of the skin: where and how it appears help determine therapy," Postgraduate Medicine, vol. 109, no. 1, pp. 117-132, 2001.

[3] I. Weitzman and R. C. Summerbell, "The dermatophytes," Clinical Microbiology Reviews, vol. 8, pp. 240-259, 1995.

[4] J. Faergemann and R. Baran, "Epidemiology, clinical presentation and diagnosis of onychomycosis," British Journal of Dermatology, vol. 149, supplement 65, pp. 1-4, 2003.

[5] B. E. Elewski, "The effect of toenail onychomycosis on patient quality of life," International Journal of Dermatology, vol. 36, no. 10, pp. 754-756, 1997.

[6] B. Havlickova, V. A. Czaika, and M. Friedrich, "Epidemiological trends in skin mycoses worldwide," Mycoses, vol. 52, supplement 4, pp. 2-15, 2008.

[7] E. Haneke and D. Roseeuw, "The scope of onychomycosis: epidemiology and clinical features," International Journal of Dermatology, vol. 38, supplement 2, pp. 7-12, 1999.

[8] S. Cheng and L. Chong, "A prospective epidemiological study on tinea pedis and onychomycosis in Hong Kong," Chinese Medical Journal, vol. 115, no. 6, pp. 860-865, 2002.

[9] A. A. Panackal, E. F. Halpern, and A. J. Watson, "Cutaneous fungal infections in the United States: analysis of the national ambulatory medical care survey (NAMCS) and national hospital ambulatory medical care survey (NHAMCS), 1995-2004," International Journal of Dermatology, vol. 48, no. 7, pp. 704-712, 2009.

[10] A. Djeridane, Y. Djeridane, and A. Ammar-Khodja, "Epidemiological and aetiological study on tinea pedis and onychomycosis in Algeria," Mycoses, vol. 49, no. 3, pp. 190-196, 2006.

[11] I. Halim, F. El Kadioui, and M. Soussi Abdallaoui, "Onychomycosis in Casablanca (Morocco)," Journal de Mycologie Medicale, vol. 23, no. 1, pp. 9-14, 2013.

[12] N. El Fekih, I. Belghith, S. Trabelsi, H. Skhiri-Aounallah, S. Khaled, and B. Fazaa, "Epidemiological and etiological study of foot mycosis in Tunisia," Actas Dermo-Sifiliograficas, vol. 103, no. 6, pp. 520-524, 2012.

[13] I. Dhib, A. Fathallah, A. Yaacoub, R. Zemni, R. Gaha, and M. B. Said, "Clinical and mycological features of onychomycosis in central Tunisia: a 22 years retrospective study (1986-2007)," Mycoses, vol. 56, no. 3, pp. 273-280, 2013.

[14] M. C. Seck, D. Ndiaye, K. Diongue et al., "Mycological profile of onychomycosis in Dakar (Senegal)," Journal de Mycologie Medicale, vol. 24, no. 2, pp. 124-128, 2014.

[15] S. Anane, O. Chtourou, A. Chedi et al., "Onychomycosis in the elderly," Annales de Dermatologie et de Venereologie, vol. 134, no. 10, pp. 743-747, 2007.
[16] P. Godoy-Martinez, F. G. Nunes, J. Tomimori-Yamashita et al., "Onychomycosis in São Paulo, Brazil," Mycopathologia, vol. 168, no. 3, pp. 111-116, 2009.

[17] Y. Ogasawara, M. Hiruma, M. Muto, and H. Ogawa, "Clinical and mycological study of occult tinea pedis and tinea unguium in dermatological patients from Tokyo," Mycoses, vol. 46, no. 34, pp. 114-119, 2003.

[18] H. Järv, P. Naaber, S. Kaur, M. Eisen, and H. Silm, "Toenail onychomycosis in Estonia," Mycoses, vol. 47, no. 1-2, pp. 57-61, 2004.

[19] M. Papini, B. M. Piraccini, E. Difonzo, and A. Brunoro, "Epidemiology of onychomycosis in Italy: prevalence data and risk factor identification," Mycoses, vol. 58, no. 11, pp. 659-664, 2015.

[20] J. O. Lopes, S. H. Alves, C. R. Mari et al., "A ten-year survey of onychomycosis in the Central Region of the Rio Grande do Sul, Brazil," Revista do Instituto de Medicina Tropical de São Paulo, vol. 41, no. 3, pp. 147-149, 1999.

[21] M. Pérez-González, J. M. Torres-Rodríguez, A. Martínez-Roig et al., "Prevalence of tinea pedis, tinea unguium of toenails and tinea capitis in school children from Barcelona," Revista Iberoamericana de Micologia, vol. 26, no. 4, pp. 228-232, 2009.

[22] T. Gunduz, D. Y. Metin, T. Sacar et al., "Onychomycosis in primary school children: association with socioeconomic conditions," Mycoses, vol. 49, no. 5, pp. 431-433, 2006.

[23] M. Ilkit and M. Durdu, "Tinea pedis: the etiology and global epidemiology of a common fungal infection," Critical Reviews in Microbiology, vol. 41, no. 3, pp. 374-388, 2015.

[24] J. C. Szepietowski, A. Reich, E. Garlowska, M. Kulig, and E. Baran, "Factors influencing coexistence of toenail onychomycosis with tinea pedis and other dermatomycoses: a survey of 2761 patients," Archives of Dermatology, vol. 142, no. 10, pp. 12791284, 2006.

[25] I. Effendy, M. Lecha, M. F. De Chauvin, N. Di Chiacchio, and R. Baran, "Epidemiology and clinical classification of onychomycosis," Journal of the European Academy of Dermatology and Venereology, vol. 19, no. 1, pp. 8-12, 2005.

[26] S. Anane, K. Aoun, N. Zallagua, and A. Bouratbine, "Onychomycosis in tunis area: Epidemiological and mycological data," Annales de Dermatologie et de Venereologie, vol. 128, no. 6-7, pp. 733-736, 2001.

[27] S. Nkondjo Minkoumou, V. Fabrizi, and M. Papini, "Onychomycosis in Cameroon: a clinical and epidemiological study among dermatological patients," International Journal of Dermatology, vol. 51, no. 12, pp. 1474-1477, 2012.

[28] N. Aste, M. Pau, N. Aste, and P. Biggio, "Tinea pedis observed in Cagliari, Italy, between 1996 and 2000," Mycoses, vol. 46, no. 1-2, pp. 38-41, 2003.

[29] C. Mügge, U.-F. Haustein, and P. Nenoff, "Causative agents of onychomycosis-a retrospective study," Journal of the German Society of Dermatology, vol. 4, no. 3, pp. 218-228, 2006.

[30] I. T. Drakensjö and E. Chryssanthou, "Epidemiology of dermatophyte infections in Stockholm, Sweden: a retrospective study from 2005-2009," Medical Mycology, vol. 49, no. 5, pp. 484-488, 2011.

[31] F. Foulet, G. Cremer, E. Bourdon-Lanoy et al., "Frequency of plantar dermatophytosis: a retrospective study 2002-2003," Annales de Dermatologie et de Venereologie, vol. 134, no. 4, pp. 343-345, 2007.

[32] A. K. Gupta, H. C. Jain, C. W. Lynde, P. MacDonald, E. A. Cooper, and R. C. Summerbell, "Prevalence and epidemiology 
of onychomycosis in patients visiting physicians' offices: a multicenter Canadian survey of 15,000 patients," Journal of the American Academy of Dermatology, vol. 43, no. 2, pp. 244-248, 2000.

[33] E. T. M. Mapelli, L. Colombo, E. Crespi, and S. Menni, “Toenail onychomycosis due to Trichophyton violaceum complex (An unusual, emerging localization of this anthropophilic dermatophyle)," Mycoses, vol. 55, no. 2, pp. 193-194, 2012.

[34] A. Tosti, B. M. Piraccini, and S. Lorenzi, "Onychomycosis caused by nondermatophytic molds: clinical features and response to treatment of 59 cases," Journal of the American Academy of Dermatology, vol. 42, no. 2, pp. 217-224, 2000.

[35] A. K. Gupta, E. A. Cooper, P. MacDonald, and R. C. Summerbell, "Utility of inoculum counting (Walshe and English Criteria) in clinical diagnosis of onychomycosis caused by nondermatophytic filamentous fungi," Journal of Clinical Microbiology, vol. 39, no. 6, pp. 2115-2121, 2001.

[36] M. A. Ghannoum, R. A. Hajjeh, R. Scher et al., "A large-scale North American study of fungal isolates from nails: the frequency of onychomycosis, fungal distribution, and antifungal susceptibility patterns," Journal of the American Academy of Dermatology, vol. 43, no. 4, pp. 641-648, 2000.

[37] C. Gianni, A. Cerri, and C. Crosti, "Non-dermatophytic onychomycosis. An understimated entity? A study of 51 cases," Mycoses, vol. 43, no. 1-2, pp. 29-33, 2000.

[38] F.-Z. M. Hajoui, Z. Zeroual, B. Ghfir, A. Moustachi, M. Lyagoubi, and S. Aoufi, "The mould onychomycosis in Morocco: about 150 isolated cases in 20 years," Journal de Mycologie Medicale, vol. 22, no. 3, pp. 221-224, 2012.

[39] D. Chabasse and M. Pihet, "Onychomycoses due to molds," Journal de Mycologie Medicale, vol. 24, no. 4, pp. 261-268, 2014.

[40] W. Boonchai, C. Maungprasat, K. Kulthanan, and P. Suthipinittham, "Clinical characteristics and mycology of onychomycosis in autoimmune patients," Journal of the Medical Association of Thailand, vol. 86, no. 11, pp. 995-1000, 2003.

[41] M. Del Mar, S. De Ocariz, R. Arenas, G. A. Ranero-Juárez, F. Farrera-Esponda, and E. Monroy-Ramos, "Frequency of toenail onychomycosis in patients with cutaneous manifestations of chronic venous insufficiency," International Journal of Dermatology, vol. 40, no. 1, pp. 18-25, 2001.

[42] N. El Fékih, B. Fazaa, B. Zouari et al., "Fungal foot infections in diabetic patients: a prospective study of 150 patients," Journal de Mycologie Medicale, vol. 19, no. 1, pp. 29-33, 2009.

[43] A. Surjushe, R. Kamath, C. Oberai et al., "A clinical and mycological study of onychomycosis in HIV infection," Indian Journal of Dermatology, Venereology and Leprology, vol. 73, no. 6, pp. 397-401, 2007.

[44] A. K. Gupta, C. W. Lynde, H. C. Jain et al., "A higher prevalence of onychomycosis in psoriatics compared with non-psoriatics: a multicentre study," British Journal of Dermatology, vol. 136, no. 5, pp. 786-789, 1997.

[45] P. V. Venugopal and T. V. Venugopal, "Superficial mycoses in Saudi Arabia," Australasian Journal of Dermatology, vol. 33, no. 1, pp. 45-48, 1992.

[46] N. Raboobee, J. Aboobaker, and A. K. Peer, "Tinea pedis et unguium in the Muslim community of Durban, South Africa," International Journal of Dermatology, vol. 37, no. 10, pp. 759-765, 1998.

[47] M. Ilkit, F. Tanir, S. Hazar, T. Gümüşay, and M. Akbaba, "Epidemiology of tinea pedis and toenail tinea unguium in worshippers in the mosques in Adana, Turkey," Journal of Dermatology, vol. 32, no. 9, pp. 698-704, 2005.
[48] C. E. Laraqui, A. Caubet, A. Benghalem et al., "Hygiene, working conditions and professional risks in the Moorish 'hammams++' in Marrakech,' Sante, vol. 10, no. 1, pp. 19-26, 2000.

[49] O. Welsh, E. Welsh, J. Ocampo-Candiani, M. Gomez, and L. Vera-Cabrera, "Dermatophytoses in Monterrey, México," Mycoses, vol. 49, no. 2, pp. 119-123, 2006.

[50] A. Tosti, R. Hay, and R. Arenas-Guzmán, "Patients at risk of onychomycosis-risk factor identification and active prevention," Journal of the European Academy of Dermatology and Venereology, vol. 19, no. 1, pp. 13-16, 2005.

[51] J. E. Arrese and G. E. Piérard, “Treatment failures and relapses in onychomycosis: a stubborn clinical problem," Dermatology, vol. 207, no. 3, pp. 255-260, 2003. 


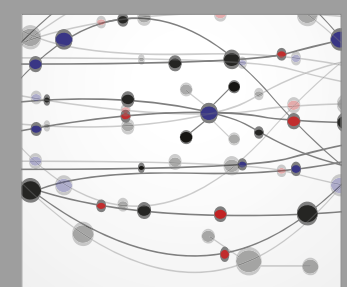

The Scientific World Journal
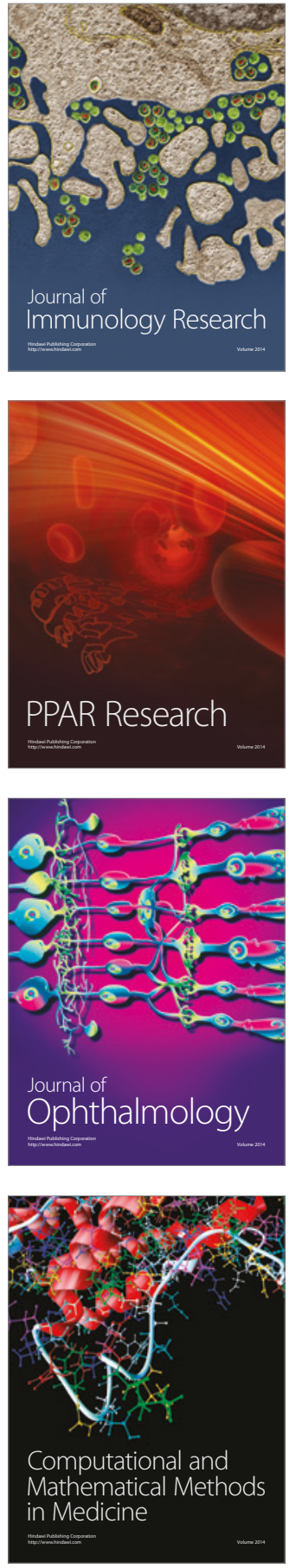

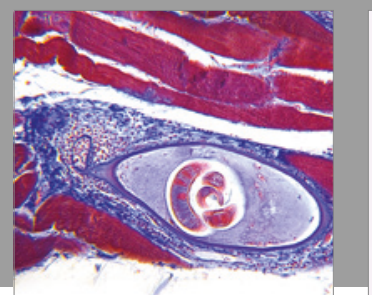

Gastroenterology Research and Practice
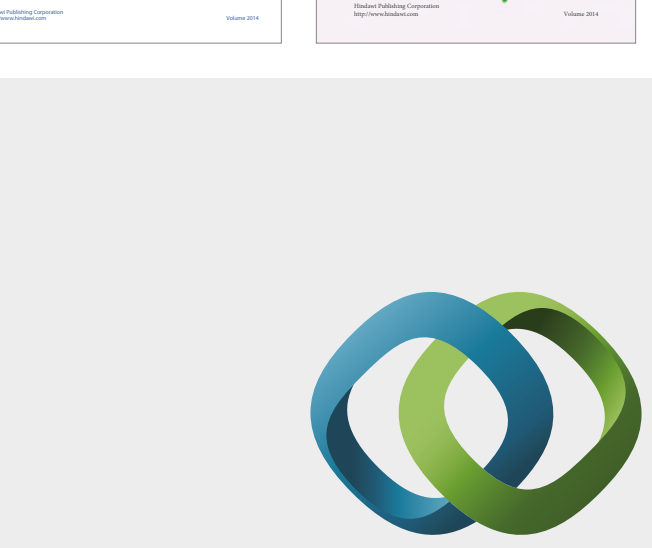

\section{Hindawi}

Submit your manuscripts at

https://www.hindawi.com
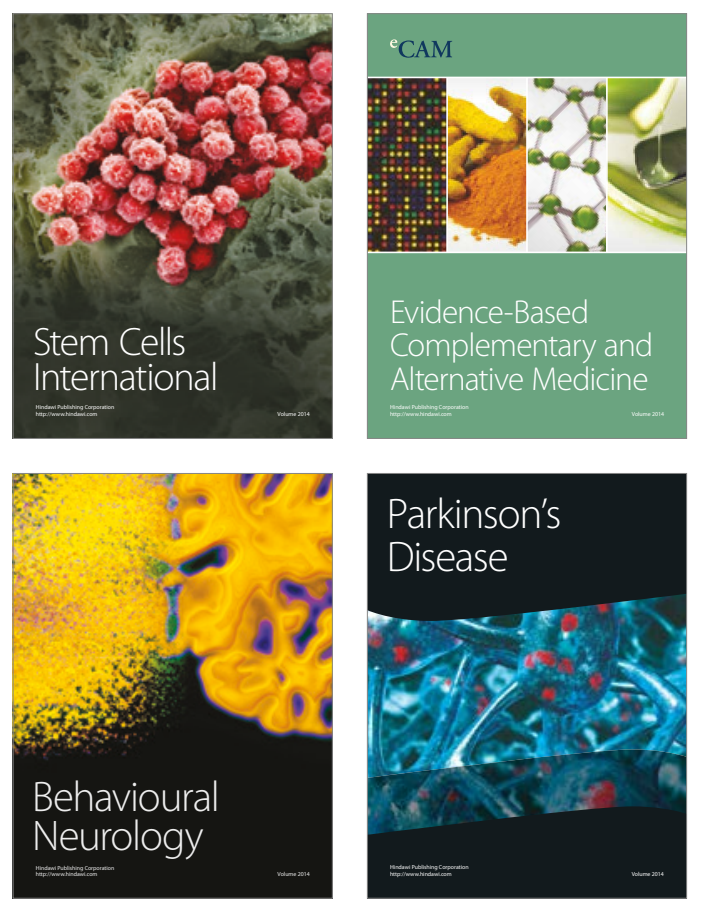
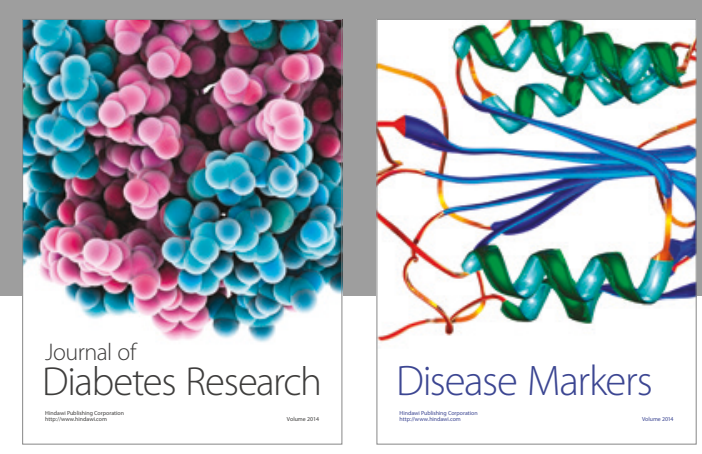

Disease Markers
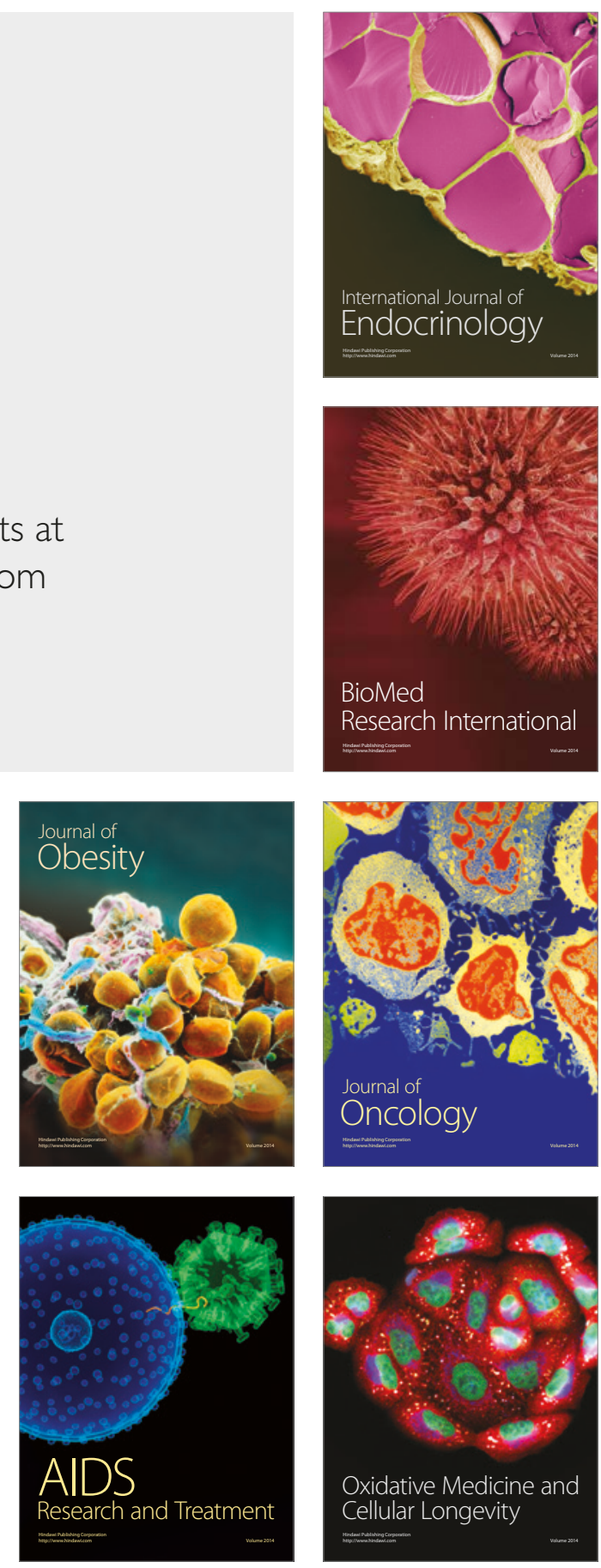